\title{
Case-control study of anthropometric measures and testicular cancer risk
}

\section{Fabrizio Giannandrea*, Donatella Paoli, Francesco Lombardo, Andrea Lenzi and Loredana Gandini}

Laboratory of Seminology - Semen Bank, Department of Experimental Medicine, University of Rome "La Sapienza," Rome, Italy

\section{Edited by:}

Alberto Ferlin, University of Padova, Italy

\section{Reviewed by:}

Giovanni Vitale, Istituto Auxologico Italiano - Universita' Degli Studi di

Milano, Italy

Gregory A. Kaltsas, National

University of Athens, Greece

*Correspondence:

Fabrizio Giannandrea, Laboratory of Seminology - Semen Bank,

Department of Experimental

Medicine, University of Rome

"La Sapienza," P.le Aldo Moro,

500185 Rome, Italy.

e-mail: fabrizio.giannandrea@

uniroma1.it
The etiology of testicular germ cell tumors (TGCTs) is poorly understood. Recent epidemiological findings suggest that, TGCT risk is determined very early in life, although the available data are still conflicting. The rapid growth of the testes during puberty may be another period of vulnerability. Body size has received increasing attention as possible risk factor for TC. To clarify the relation of body size and its anthropometric variables to TGCT risk, the authors analyzed data from 272 cases and 382 controls with regard to height $(\mathrm{cm})$, weight $(\mathrm{Kg})$, and body mass index $\left(\mathrm{BMl} ; \mathrm{kg} / \mathrm{m}^{2}\right)$. Overall, participants in the highest quartile of height were more likely to be diagnosed with TGCTs than participants in the lowest quartile of height, OR 2.22 (95\% confidence intervals (CI): 1.25-3.93; adjusted; $p_{\text {trend }}=0.033$ ). Moreover, histological seminoma subgroup was significantly associated with tallness, very tall men $(>182 \mathrm{~cm})$ having a seminoma TGCT risk of OR $=2.44$ (95\% confidence intervals (Cl): 1.19-4.97; adjusted; $p_{\text {trend }}=0.011$ ). There was also a significant inverse association of TGCT with increasing BMI ( $p_{\text {trend }}=0.001$; age-adjusted analysis) and this association was equally present in both histological subgroups. These preliminary results indicate that testicular cancer (TC) is inversely associated with $\mathrm{BMI}$ and positively associated with height, in particular with seminoma subtype. Several studies have reported similar findings on body size. As adult height is largely determined by high-calorie intake in childhood and influenced by hormonal factors at puberty, increased attention to postnatal exposures in this interval may help elucidate the etiology of TGCTs.

Keywords: testicular cancer, height, weight, body mass index, body size

\section{INTRODUCTION}

Testicular cancer (TC) is the most common type of malignancy in men aged 15-40 years (Dieckmann and Pichlmeier, 2004). The incidence of TC has more than doubled worldwide over the last 40 years in several populations (Purdue et al., 2005; Bray et al., 2006). The reasons of this rise are not entirely clear (McGlynn and Cook, 2009).

Evidence of incidence peak of TC among young adults suggests that causal factors operate very early in life (Bray et al., 2006). One theory attributes it to the increase in endogenous estrogen levels during prenatal life and/or later exposures to various occupational and environmental estrogenic chemicals, termed endocrine-disrupting chemicals (EDCs) (Toppari et al., 1996; Sharpe, 2003; Cook et al., 2011; Giannandrea et al., 2011). According to this hypothesis, these exposures are also risk factors for other male reproductive disorder, such as cryptorchism and impaired sperm quality (Skakkebaek et al., 2001; Storgaard et al., 2006). Recently, it has been suggested that post-natal exposures might increase the risk of developing TC, and that secretion of sex hormones, which are involved in the growth and the development of the testicle, might be instrumental in TC progression (James, 2010; Trabert et al., 2011).

One possible risk factor that has received increasing attention is body size, which is determined by hereditary, nutritional, and hormonal factors (Dieckmann and Pichlmeier, 2002). Height, weight, and body mass index (BMI) have been examined in a number of studies, with mixed results (Lerro et al., 2010). Several studies have reported inverse associations of TC with BMI (Petridou et al., 1997; Bjørge et al., 2006; Lerro et al., 2010). A number of studies have reported that increased adult height may be a risk factor for TC, thereby suggesting that factors related to adult height may also be related to risk of these tumors (Richiardi et al., 2003; Dieckmann et al., 2008; Lerro et al., 2010). One explanation for the height association may be that better childhood nutrition increases both adult height and risk of TC. This hypothesis is supported by epidemiological observations of constantly increasing incidence of TC since the beginning of the twentieth century with the only major interruption in this trend occurring for men born during World War II or immediately thereafter, when food availability had been dramatically reduced (Moller, 1989; Aschim et al., 2005; Giannandrea, 2009).

To clarify the relation of anthropometric variables to TGCT risk and to one another, we analyzed data from 321 cases and 465 controls enrolled at our laboratory with regard to height $(\mathrm{cm})$, weight $(\mathrm{Kg})$ and body mass index $\left(\mathrm{BMI} ; \mathrm{kg} / \mathrm{m}^{2}\right)$.

\section{MATERIALS AND METHODS}

Participants among 321 consecutive patients affected by TC and 465 controls were originally selected at the Laboratory of Seminology, Semen Bank, Department of Experimental 
Medicine, University of Rome "La Sapienza," Rome, Italy. Controls were recruited among healthy men who underwent to seminal analyses in order to ascertain their fertility status before getting married. We excluded men with conditions possibly associated with impaired sperm quality, and/or with a history of neoplastic pathologies to provide the most suitable control group. Only men aged 20-55 years at diagnosis were eligible for the study. Inclusion was restricted to this age range as normal height growth is complete between 16 and 20 years, while there is a characteristic decline in height growth in adulthood. Some of the controls who underwent to seminal analyses were men affected by severe obesity according to WHO classification (WHO, 2000), and therefore, this group was excluded from both cases and controls in order to avoid the confounding effect of this condition on our study variables.

Only patients with tumors of germ cell origin were included in the analyses. We categorized the cases into the two major histopathologic subgroups: seminomas or non-seminomas, which include embryonal carcinomas, endodermal sinus tumors, teratomas, choriocarcinomas, or germ cell tumors of mixed morphology. Our study population was therefore finally restricted to a total of 272 cases and 382 controls, according to the selection criteria described above.

Statistical analyses were performed by use of a SPSS statistical package. All tests were two sided, with $p<0.05$ defined as statistically significant. Logistic regression models were calculated to obtain odds ratios (OR) and 95\% confidence intervals (CIs) with adjustment for the potentially confounding factors, height, weight, and age at diagnosis (Armitage et al., 2001). ORs, confidence limits, and $p$ values were adjusted for age because of imbalance of age distribution between cases and controls.

Height, weight, and BMI were categorized into quartiles on the basis of the distribution among the entire study group. Categories were 20-29 years, 30-34 years, 35-39 years, and $\geq 40$ years with respect $t$ to age; $\leq 173 \mathrm{~cm}, 174-178 \mathrm{~cm}, 179-182 \mathrm{~cm}$, and $>182$ with respect to height. BMI [weight (in kilograms) divided by height (in meters) squared] was calculated for each subject and categorized into slim (BMI $<23.15 \mathrm{~kg} / \mathrm{m}^{2}$ ), normal weight (BMI $23.16-24.97 \mathrm{~kg} / \mathrm{m}^{2}$ ), overweight (BMI $24.98-27.4 \mathrm{~kg} / \mathrm{m}^{2}$ ), and obese $\left(\mathrm{BMI} \geq 27.4 \mathrm{~kg} / \mathrm{m}^{2}\right)$. Tests for trend were performed by use of the categorized variables.

\section{RESULTS}

The descriptive tabulation of anthropometric measures distribution of cases and controls is shown in Table 1. The mean ages of the non-seminoma cases was lower than the mean age of the seminoma cases (30.6 years, standard deviation (SD): 6.0 vs. 34.1 years, SD: $5.9 ; p<0.05)$. It is well-acknowledged that nonseminoma peak at younger age than seminoma. Therefore, the risk of TC decrease with increasing age at diagnosis, with nonseminomas having a more significant inverse relationship with age $\left(p_{\text {trend }}<0.001\right)$ than seminomas $\left(p_{\text {trend }}=0.021\right)$ (Table 2$)$. The relations of anthropometric variables and TC risk are shown in Table 2. In the multivariate analysis, BMI was inversely associated and height was positively associated with risk of TC (Table 2).

Overall, participants in the highest quartile of height were more likely to be diagnosed with testicular germ cell tumors (TGCTs) than participants in the lowest quartile of height, OR 2.22 (95\% confidence intervals (CI): $1.25-3.93$; adjusted; $p_{\text {trend }}=$ $0.033)$. Moreover, histological seminoma subgroup was significantly associated with tallness, very tall men $(>182 \mathrm{~cm})$ having a seminoma TGCT risk of OR $=2.44$ (95\% confidence intervals $(\mathrm{CI})$ : $1.19-4.97$; adjusted; $\left.p_{\text {trend }}=0.011\right)$. The multivariateadjusted odds ratio for the highest quartile group of BMI relative to the lowest was 0.42 (95\% CI: $0.24-0.75$; $\left.p_{\text {trend }}=0.01\right)$, with no difference by histological subtype (Table 2 ). There was also a significant inverse association of TGCT with increasing weight ( $p_{\text {trend }}=0.001$; age-adjusted analysis) and this association was equally present in both histological subgroups.

\section{DISCUSSION}

These preliminary results indicate that TC is positively associated with height, in particular with seminoma subtype, and inversely related with BMI. Therefore, the present study indicated an excess of tall men in the cohort of patients with TC. To our knowledge, this study is the first to explore the relationship between tallness and the risk of TC from a southern European country. Thus far, the majority of studies on tallness in relation to the risk of TC were conducted in US and Nordic countries (Akre et al., 2000; McGlynn et al., 2007; Dieckmann et al., 2008; Cook et al., 2010; Lerro et al., 2010). Measures of adult height, as well as the incidence rate of TC, resulted both elevated among Scandinavian populations (Richiardi et al., 2003; Purdue et al., 2005).

Table 1 | Descriptive statistical analysis of anthropometric measures (Mean \pm SD).

\begin{tabular}{|c|c|c|c|c|c|}
\hline & Patients ( $n)$ & Age (years) & Height (cm) & BMI & Weight (Kg) \\
\hline Controls (C) & 382 & $35.7 \pm 7.1$ & $177.6 \pm 6.5$ & $24.7 \pm 2.0$ & $78.1 \pm 8.7$ \\
\hline All TC (TC) & 272 & $32.4 \pm 6.2$ & $177.8 \pm 6.3$ & $23.8 \pm 2.3$ & $75.5 \pm 9.0$ \\
\hline Seminoma (S) & 138 & $34.1 \pm 5.9$ & $177.5 \pm 6.1$ & $24.0 \pm 2.5$ & $75.7 \pm 9.4$ \\
\hline Nonseminoma (NS) & 134 & $30.6 \pm 6.0$ & $178.2 \pm 6.5$ & $23.6 \pm 2.2$ & $75.3 \pm 8.6$ \\
\hline TC vs. C & & $\mathrm{b}$ & a & a & a \\
\hline S vs. C & & a & a & a & a \\
\hline NS vs. C & & $b$ & a & a & a \\
\hline
\end{tabular}

${ }^{a}$ Not significant.

${ }^{b} p<0.05$. 


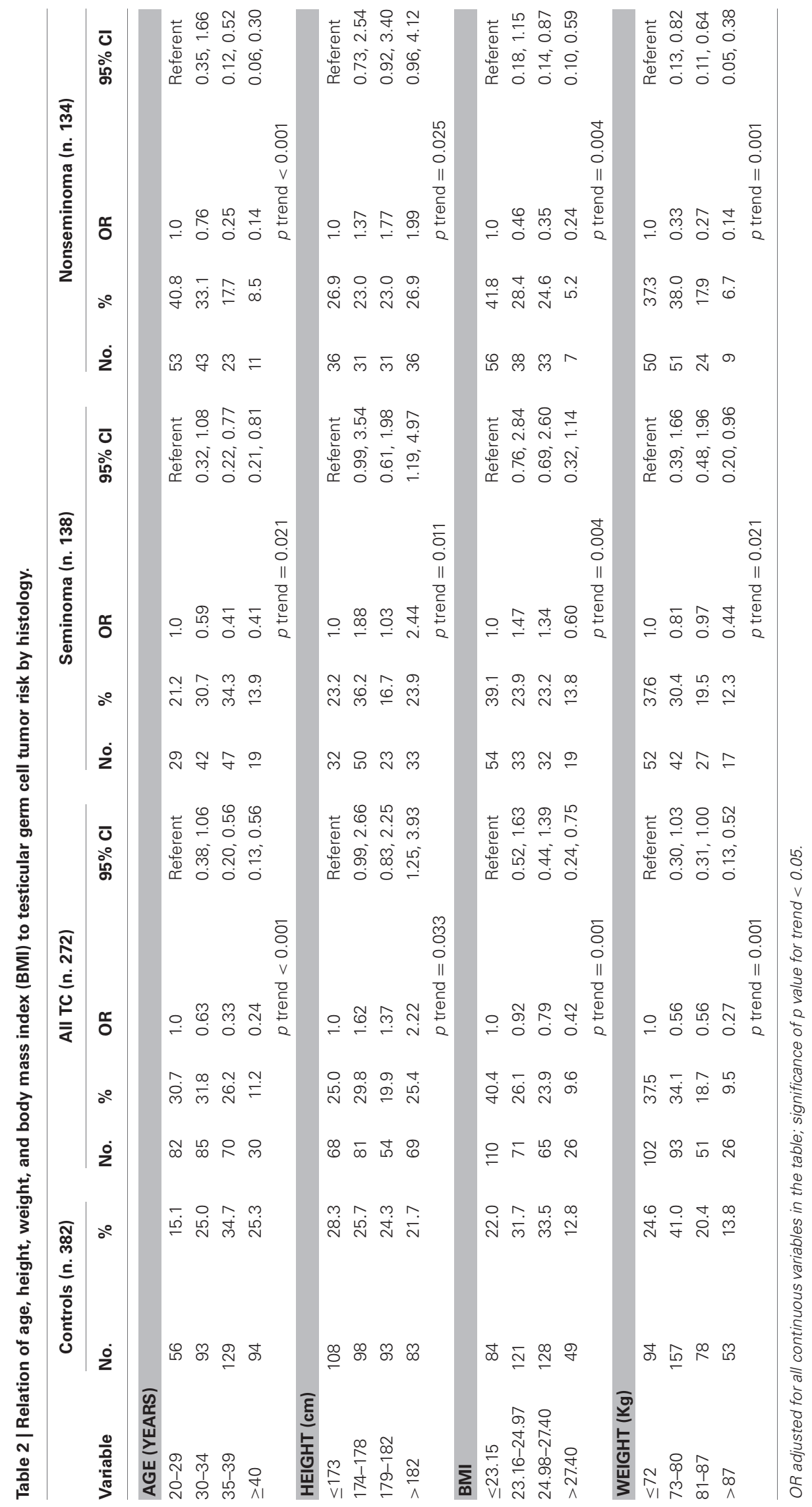


Though differences in genetic backgrounds among Scandinavian and southern European populations exist, these preliminary findings imply that possible postnatal exposures may play an important role in determining risk of TC. As adult height is largely determined during the first 2 years of life, it may be postulated that high calorie nutrition after birth could have a role in TC pathogenesis (Frankel et al., 1998; McGlynn et al., 2007; Giannandrea, 2009). In addition, as final adult height is strongly dependent on testis sex-steroids (Veldhuis et al., 2005) a correlation between height and TC risk may suggest that androgen secretion during puberty might be involved in TC progression. One further height-related factor may be insulin-like growth factor (IGF) and the IGF pathway, which is also involved in the control of spermatogenesis (Gunnell et al., 2001; Giovannucci et al., 2004). Increased serum IGF-1 levels were associated with increased height has also been reported in several studies (Chia et al., 2008).

Height has been positively associated with risk of TC in the majority of studies in which it has been examined (Akre et al., 2000; McGlynn et al., 2007; Dieckmann et al., 2008; Cook et al., 2010; Lerro et al., 2010). Akre et al. (2000) found a statistically significant increased risk of TC associated with greater height, and this association was particularly evident in men with seminomas. Dieckmann et al. (2008) found that very tall men $(>195 \mathrm{~cm})$ carried a TC risk of OR: 3.35 (95\% confidence intervals (CI): 2.88-3.90; adjusted). In the STEED Study, increased height was significantly related to risk of TC (OR: 1.85; CI 95\%: 0.71, 1.32) (McGlynn et al., 2007; Lerro et al., 2010).

A number of studies have so far reported an inverse relationship between BMI and TGCTs, although the available results are still conflicting, with some studies reporting null findings (Petridou et al., 1997; Bjørge et al., 2006; Lerro et al., 2010). A recent meta-analysis conducted by Lerro et al. (2010) has produced a tentative evidence that TC risk was inversely associated with BMI, with a summary OR of 0.92 (95\% CI: $0.86-0.98$; $p=0.011)$. The biological reasons of this negative association are likely to be more complex of those contemplated to explain the association of TC with tallness. Some authors have suggested that lower BMI found in previous studies could also be a mathematical artifact as this association may be related to an excess

\section{REFERENCES}

Akre, O., Ekbom, A., Sparén, P., and Tretli, S. (2000). Body size and testicular cancer. J. Natl. Cancer Inst. 92, 1093-1096.

Armitage, P., Berry, G., and Matthews, J. N. S. (2001). Statistical Methods in Medical Research. Oxford: Blackwell Scientific.

Aschim, E. L., Grotmol, T., Tretli, S., and Haugen, T. B. (2005). Is there an association between maternal weight and the risk of testicular cancer? An epidemiologic study of Norwegian data with emphasis on World War, II. Int. J. Cancer 116, 327-330.

of tall men in TC cohorts rather than to leanness of the patients (Dieckmann and Pichlmeier, 2002). This is due to the fact that height is squared in the denominator of the BMI-formula, lowering the numerical calculation of MBI in very tall men at hight TC risk despite normal weight. However, our study shows additional significant inverse association of TGCT with increasing weight ( $\left.p_{\text {trend }}=0.001\right)$, therefore confuting, at least in part, this suggestion.

Body size is primarily determined by hereditary, nutritional, and hormonal factors (Dieckmann and Pichlmeier, 2002). The hormonal determinants can be divided into growth hormones and sex hormones. Most previous studies on postnatal risk factors for TC have focused on endogenous sex hormones. Obesity is inversely associated with both total testosterone and sex hormone-binding globulin (Akre et al., 2000). Furthermore, obese men have increased levels of both estradiol and estrone coming mostly from extraglandular conversion of androgen precursors (Akre et al., 2000; Dieckmann and Pichlmeier, 2002).

Since testicular germ cell cancer is probably initiated in utero, postnatal hormones are likely to function as promoters. These hormones may continue to exert their effect in advanced stages of tumor development at time of puberty when the testicles grow and develop rapidly.

Adult stature can be considered a proxy of childhood nutrition, although stature is also determined by genetic and hormonal factors. It has been suggested that the trend of increasing adult height and the increasing TC incidence are biologically interconnected with improved nutrition in early life.

In summary, we have found a lower risk of TC among men with high BMI. Further investigation of this inverse relationship may be warranted, for which the present results provide only limited support. Furthermore, tallness was positively associated with risk of TC. The biologic mechanism suggested is the promotion of this cancer by sex hormones and/or growth hormones, such as growth hormone and/or IGF-I.

\section{FUNDING}

Financial support for this work was provided by a Grant from the Italian Ministry of Education and Research (MIUR-PRIN) and the University of Rome "La Sapienza" Faculty of Medicine.

R. L., Stanczyk, F. Z., et al. (2008). Insulin-like growth factor 1 , insulin-like growth factor-binding protein 3, and testicular germ-cell tumor risk. Am. J. Epidemiol. 167, 1438-1445.

Cook, M. B., Akre, O., Forman, D., Madigan, M. P., Richiardi, L., and McGlynn, K. A. (2010). A systematic review and meta-analysis of perinatal variables in relation to the risk of testicular cancer: experiences of the son. Int. J. Epidemiol. 39, 1605-1618.

Cook, M. B., Trabert, B., and McGlynn, K. A. (2011). Organochlorine compounds and testicular dysgenesis syndrome: human data. Int. J. Androl. 34, e68-e84.

Dieckmann, K. P., Hartmann, J. T., Classen, J., Lüdde, R., Diederichs, M., and Pichlmeier, U. (2008). Tallness is associated with risk of testicular cancer: evidence for the nutrition hypothesis. Br. J. Cancer 99, 1517-1521.

Dieckmann, K. P., and Pichlmeier, U. (2002). Is risk of testicular cancer related to body size? Eur. Urol. 42, 564-569.

Dieckmann, K. P., and Pichlmeier, U. (2004). Clinical epidemiology of testicular germ cell tumors. World J. Urol. 22, 2-14. 
Frankel, S., Gunnell, D. J., Peters, T. J., Maynard, M., and Davey Smith, G. (1998). Childhood energy intake and adult mortality from cancer: the Boyd Orr Cohort Study. BMJ 316, 499-504.

Giannandrea, F. (2009). Correlation analysis of cocoa consumption data with worldwide incidence rates of testicular cancer and hypospadias. Int. J. Environ. Res. Public Health 6, 568-578.

Giannandrea, F., Gandini, L., Paoli, D., Turci, R., and Figà-Talamanca, I. (2011). Pesticide exposure and serum organochlorine residuals among testicular cancer patients and healthy controls. J. Environ. Sci. Health B 46, 780-787.

Giovannucci, E., Rimm, E. B., Liu, Y., and Willett, W. C. (2004). Height, predictors of C-peptide and cancer risk in men. Int. J. Epidemiol. 33, 217-225.

Gunnell, D., Okasha, M., Smith, G. D., Oliver, S. E., Sandhu, J., and Holly, J. M. (2001). Height, leg length, and cancer risk: a systematic review. Epidemiol. Rev. 23, 313-342.

James, W. H. (2010). Further grounds for abandoning the concept of testicular dysgenesis syndrome: a response to the paper of Akre and Richiardi. Hum. Reprod. 25, 1084-1086.

Lerro, C. C., McGlynn, K. A., and Cook, M. B. (2010). A systematic review and meta-analysis of the relationship between body size and testicular cancer. Br. J. Cancer 103, 1467-1474.

McGlynn, K. A., and Cook, M. B. (2009). Etiologic factors in testicular germ-cell tumors. Future Oncol. 5, 1389-1402.

McGlynn, K. A., Sakoda, L. C., Rubertone, M. V., Sesterhenn, I. A., Lyu, C., Graubard, B. I., et al. (2007). Body size, dairy consumption, puberty, and risk of testicular germ cell tumors. Am. J. Epidemiol. 165, 355-363.

Moller, H. (1989). Decreased testicular cancer risk in men born in wartime. J. Natl. Cancer Inst. 81, 1668-1669.

Petridou, E., Roukas, K. I., Dessypris, N., Aravantinos, G., Bafaloukos, D., Efraimidis, A., et al. (1997). Baldness and other correlates of sex hormones in relation to testicular cancer. Int. J. Cancer 71, 982-985.

Purdue, M. P., Devesa, S. S., Sigurdson, A. J., and McGlynn, K. A. (2005). International patterns and trends in testis cancer incidence. Int. J. Cancer $115,822-827$.

Richiardi, L., Askling, J., Granath, F., and Akre, O. (2003). Body size at birth and adulthood and the risk for germ-cell testicular cancer. Cancer Epidemiol. Biomarkers Prev. 12, 669-673.
Sharpe, R. M. (2003). The 'oestrogen hypothesis': where do we stand now? Int. J. Androl. 26, 2-15.

Skakkebaek, N. E., Rajpert-De Meyts, E., and Main, K. M. (2001) Testicular dysgenesis syndrome: an increasingly common developmental disorder with environmental aspects. Hum. Reprod. 16, 972-978.

Storgaard, L., Bonde, J. P., and Olsen, J. (2006). Male reproductive disorders in humans and prenatal indicators of estrogen exposure. A review of published epidemiological studies. Reprod. Toxicol. 21, 4-15.

Toppari, J., Larsen, J. C., Christiansen, P., Giwercman, A., Grandjean, P., Guillette, L. J. Jr., et al. (1996). Male reproductive health and environmental xenoestrogens. Environ. Health Perspect. 104(Suppl. 4), 741-803.

Trabert, B., Sigurdson, A. J., Sweeney, A. M., Amato, R. J., Strom, S. S., and McGlynn, K. A. (2011). Baldness, acne and testicular germ cell tumours. Int. J. Androl. 34, e59-e67.

Veldhuis, J. D., Roemmich, J. N., Richmond, E. J., Rogol, A. D., Lovejoy, J. C., Sheffield-Moore, M., et al. (2005). Endocrine control of body composition in infancy, childhood, and puberty. Endocr. Rev. 26, 114-146.
WHO. (2000). Obesity: Preventing and Managing the Global Epidemic. WHO Obesity Technical Report Series 894. World Health Organization Geneva, Switzerland.

Conflict of Interest Statement: The authors declare that the research was conducted in the absence of any commercial or financial relationships that could be construed as a potential conflict of interest.

Received: 30 September 2012; paper pending published: 22 October 2012; accepted: 06 November 2012; published online: 26 November 2012.

Citation: Giannandrea F, Paoli D, Lombardo F, Lenzi A and Gandini L (2012) Case-control study of anthropometric measures and testicular cancer risk. Front. Endocrin. 3:144. doi: 10.3389/fendo.2012.00144

This article was submitted to Frontiers in Cancer Endocrinology, a specialty of Frontiers in Endocrinology.

Copyright (C) 2012 Giannandrea, Paoli, Lombardo, Lenzi and Gandini. This is an open-access article distributed under the terms of the Creative Commons Attribution License, which permits use, distribution and reproduction in other forums, provided the original authors and source are credited and subject to any copyright notices concerning any thirdparty graphics etc. 